\title{
Downregulation of long non-coding RNA TRIM52-AS1 functions as a tumor suppressor in renal cell carcinoma
}

\author{
ZAN LIU $^{1}$, HAI-YAN YAN ${ }^{2}$, SHUN-YAO XIA ${ }^{1}$, CHENG ZHANG $^{1}$ and YOU-CHENG XIU ${ }^{1}$ \\ Departments of ${ }^{1}$ Urology and ${ }^{2}$ Anesthesiology, The First Affiliated Hospital of Harbin Medical University, \\ Harbin, Heilongjiang 150001, P.R. China
}

Received March 27, 2015; Accepted December 30, 2015

DOI: $10.3892 / \mathrm{mmr} .2016 .4908$

\begin{abstract}
Long non-coding RNAs (lncRNAs) are important regulators of gene expression, interacting with the major pathways of cell growth, proliferation, differentiation and survival. Alterations in the function of IncRNAs promote tumor formation, progression and metastasis. The purpose of the present study was to identify novel tumor suppressor lncRNAs, and elucidate their physiological function and mechanism in renal cell carcinoma (RCC). The results of the present study revealed that the expression of the IncRNA, TRIM52-AS1, was downregulated in RCC, which was demonstrated using reverse transcription-quantitative polymerase chain reaction analysis. Furthermore, the effects of TRIM52-AS1 on proliferation, cell migration and apoptosis were analyzed using a wound scratch assay, a 3-(4,5-dimethylthiazol-2yl)-2,5-diphenyl tetrazolium bromide assay and flow cytometric analysis, respectively. The overexpression of TRIM52-AS1 using a synthesized vector significantly suppressed cell migration and proliferation, and induced apoptosis of the RCC cells in vitro, and interference of its expression led to the opposite effects. The present study was the first, to the best of our knowledge, to demonstrate that TRIM52-AS1 functions as a tumor suppressor in RCC. Further investigation is required to elucidate the molecular mechanisms underlying the effects of TRIM52-AS1 in the development of RCC.
\end{abstract}

\section{Introduction}

Renal cell carcinoma ( $\mathrm{RCC}$ ) tumors originate in the renal cortex, and account for $\sim 3 \%$ of adult malignancies and almost $90 \%$ of all renal neoplasms $(1,2)$. Previously estimated

Correspondence to: Professor You-Cheng Xiu or Professor Cheng Zhang, Department of Urology, The First Affiliated Hospital of Harbin Medical University, 23 Youheng Street, Nangang, Harbin, Heilongjiang 150001, P.R. China

E-mail: xiuyoucheng2007@aliyun.com

E-mail: zhangcheng@163.com

Key words: renal cell carcinoma, TRIM52-AS1, downexpressed, suppressor cancer statistics showed that the incidence and mortality rates of RCC were among the 10 leading types of cancer in the USA, with $>65,150$ new cases and a mortality rate of $>8,780$ recorded in 2013 (3). RCC is a relatively asymptomatic disease, and $30 \%$ of patients with RCC develop invasive disease, commonly metastasizing to the bone, lungs, brain and liver $(4,5)$. Patients with metastatic RCC face a poor prognosis and have limited therapeutic options. Therefore, increased understanding of the molecular mechanisms involved in the progression of RCC, including its recurrence, metastasis or drug resistance, is required to provide a rationale for effective therapeutic methods for the treatment of RCC.

Long non-coding RNAs (lncRNAs), are transcripts of $>200$ bp in length with no protein-coding function (6), and represent a class of non-coding RNAs, which has received less attention in investigations. Several studies have demonstrated that IncRNAs are crucial for the regulation of chromatin structure, gene expression and translational control $(7,8)$. There is evidence to suggest that IncRNAs may regulate key cancer pathways at the transcriptional, post-transcriptional and epigenetic levels (9). Estimates suggest that the number of human lncRNAs rivals that of protein-coding genes, ranging between 10,000 and 20,000 (10). Despite these numbers, only a small number of lncRNAs have been characterized. In previous years, due to the successful application of different novel approaches, including genome-wide gene expression screening, genome-wide association studies, region-targeted association assays and conventional linkage screening, designed LncRNA arrays, RIP-RNA sequencing, transgenic expression, and gene knockdown or knockout, the functions of LncRNAs in cancer are being increasingly characterized. Accumulating data show that several identified LncRNAs are crucial in tissue carcinogenesis, invasion and metastasis (11-15).

Previous sequencing for the expression of LncRNAs showed TRIM52-AS1 was downregulated in RCC $(16,17)$. The present study was undertaken to verify the expression of TRIM52-AS1 in RCC, and to assess the impact of TRIM52-AS1 on cell proliferation, invasion and migration. The results of these investigations may elucidate whether TRIM52-AS1 functions as a tumor suppressor in RCC, and may lay the foundation for further studies regarding the pathogenesis of RCC. 


\section{Materials and methods}

Sample collection and RNA isolation. The present study was approved by the ethics committee of the First Affiliated Hospital of Harbin Medical University (Harbin, China). All $\mathrm{RCC}$ tissues and paired adjacent normal tissues used in the present study were collected from The Department of Urology of The First Affiliated Hospital of Harbin Medical University. All specimens were obtained on the basis of their availability for investigation purpose and under a protocol approved by the local medical ethics committee. Written informed consent was obtained from all patients involved in the present study. All tissue samples were reviewed and classified using hematoxylin and eosin staining and the 2009 American Joint Committee on Cancer staging system (18). The clinicopathological information of the patients is presented in Table I. The people were all renal cell (RCC) carcinoma patients. They could improve prognosis after nephrectomy. A total of 60 fresh RCC and adjacent normal tissue samples, located $2.0 \mathrm{~cm}$ from the visible RCC lesions, were obtained from patients with RCC by nephrectomy. The samples were immersed in RNAlater (Qiagen, Hilden, Germany) for $30 \mathrm{~min}$ and subsequently stored at $-80^{\circ} \mathrm{C}$. The total RNA of each sample was extracted using TRIzol reagent (Invitrogen; Thermo Fisher Scientific, Inc., Waltham, MA, USA), according to the manufacturer's protocol. All isolated RNA was quantified using a Nano-Drop ${ }^{\circledR}$ spectrophotometer. Only RNA samples with 260/280 ratios of 1.8-2.0 were used for further investigation.

Reverse transcription-quantitative polymerase chain reaction (RT-qPCR). CAKI- 2, 769- P, ACHN and 786-O renal carcinoma cell lines were obtained from the laboratory of the Institute of Urology of Shenzhen PKU-HKUST Medical Center (Shenzhen, China). Human embryonic kidney 293T cells were purchased from the Shanghai Institutes for Biological Sciences, Chinese Academy of Sciences (Shanghai, China). The cells were maintained in Dulbecco's modified Eagle's medium (Sigma-Aldrich, St. Louis, MO, USA) supplemented with $10 \%$ fetal bovine serum at $37^{\circ} \mathrm{C}$ in a humidified atmosphere with $5 \% \mathrm{CO}_{2}$. First-strand cDNA was synthesized using oligo-dT primers (cat. no. K1622; Fermentas, Waltham, MA, USA). The primer sequences specific for human TRIM52-AS1 were as follows: Forward 5'-AGAGCAAGGACTGTATGTGTTC-3' and reverse 5'-CTGGAGTGGCAGAAGTAAGG-3'; with human GAPDH as an internal control, the primer sequences for GAPDH were forward 5'-AGTGGCAAAGTGGAGATT-3' and reverse 5'-GTGGAGTCATACTGGAACA-3'. RT-qPCR was performed using a SYBR ${ }^{\circledR}$ Premix EX Taq ${ }^{\mathrm{TM}}$ II PCR kit (cat. no. RR820A; Takara Biotechnology Co., Ltd., Dalian, China), according to the manufacturer's protocol, on a Roche Light-cycler 480 Real-Time PCR System (Roche Diagnostics). Data were calculated according to the Applied Biosystems comparative quantification method (19).

Cellcultureandtransfection.Cells of thehumanrenalcarcinoma cell lines, ACHN and 786-O, were purchased from the American Type Culture Collection (Manassas, VA, USA). TRIM52-AS1 small hairpin shRNA (target sequence, 5'-GCACAGAGCAAG GACUGUAUGUGUU-3') were purchased from Genechem (Shanghai, China). The TRIM52-AS1 overexpression plasmid,
Table I. Clinical and pathologic characteristics of all analyzed samples.

\begin{tabular}{lc}
\hline Factor & Number \\
\hline Mean age (range), years & $55(25-83)$ \\
Gender (male/female) & $35 / 25$ \\
Pathology & \\
Clear cell RCC & 32 \\
Papillary RCC & 15 \\
Chromophobe RCC & 13 \\
Stage & \\
T1a & 34 \\
T1b & 16 \\
T2 & 7 \\
T3 & 2 \\
T4 & 1 \\
Fuhrman grade & \\
G1 & $5(\mathrm{~T} 1 \mathrm{a}), 4(\mathrm{~T} 1 \mathrm{~b})$ \\
G2 & 23 (T1a), 10 (T1b), 3 (T2) \\
G3 & 6 (T1a), 2 (T1b), 4 (T2), \\
G4 & 0 \\
\hline
\end{tabular}

T1a, tumors confined to the kidney, tumor size $\leq 4 \mathrm{~cm}$; T1b, tumors confined to the kidney, tumor size $>4 \mathrm{~cm}$ and $\leq 7 \mathrm{~cm}$; T2, tumors confined to the kidney, tumor size $>7 \mathrm{~cm}$; $\mathrm{T} 3$, tumor invades perivesical tissues; T4, tumor invades any of the following: Prostatic stroma, seminal vesicles, uterus, vagina, pelvic wall, abdominal wall; G1, tumor cells with small $(\sim 10 \mu \mathrm{m})$ round uniform nuclei and inconspicuous, or absent, nucleoli; G2, tumor cells with large $(\sim 15 \mu \mathrm{m})$ nuclei exhibiting irregularities in the membrane when examined under high magnification (x400); G3, tumor cells with larger $(\sim 20 \mu \mathrm{m})$ nuclei, an obvious irregular outline and prominent large nucleoli at low magnification (x100); G4: tumor cells exhibiting features similar to the grade 3 tumors with the addition of multilobed nuclei and heavy chromatin clumps. RCC, renal cell carcinoma.

TRIM52-AS1-pcDNA3.1+, was synthesized by Invitrogen (Thermo Fisher Scientific, Inc.). Approximately 400,000 renal cancer cells were cultured in six- well plates. The ACHN and 786-O cells were transfected with the TRIM52-AS1 shRNA (200 pmol/well) or TRIM52-AS1-pcDNA3.1+ (4 $\mu \mathrm{g} / \mathrm{well})$ vector using Lipofectamine 2000 (Invitrogen; Thermo Fisher Scientific, Inc.).

Cell proliferation assay. Cell proliferation was determined using a 3-(4,5-dimethylthiazol-2yl)-2,5-diphenyl tetrazolium bromide (MTT; Sigma-Aldrich) assay, performed according to the manufacturer's protocol. Briefly, the cells $\left(\sim 5 \times 10^{3}\right.$ cells $)$ were seeded into a 96 -well culture plate $24 \mathrm{~h}$ prior to transfection with the TRIM52-AS1 shRNA (200 pmol/well) or TRIM52-AS1-pcDNA3.1+ (4 $\mu \mathrm{g}$ /well)vector. At 0, 24, 48 or $72 \mathrm{~h}$ post-transfection, $20 \mu \mathrm{l}$ MTT $(5 \mathrm{mg} / \mathrm{ml})$ was added to each well, and the plates were incubated for $4 \mathrm{~h}$ at $37^{\circ} \mathrm{C}$. Subsequently, the MTT medium mixtures were discarded, and $150 \mu \mathrm{l}$ dimethyl sulfoxide was added to each well, and agitated for $10 \mathrm{~min}$ at room temperature to solubilize 
A

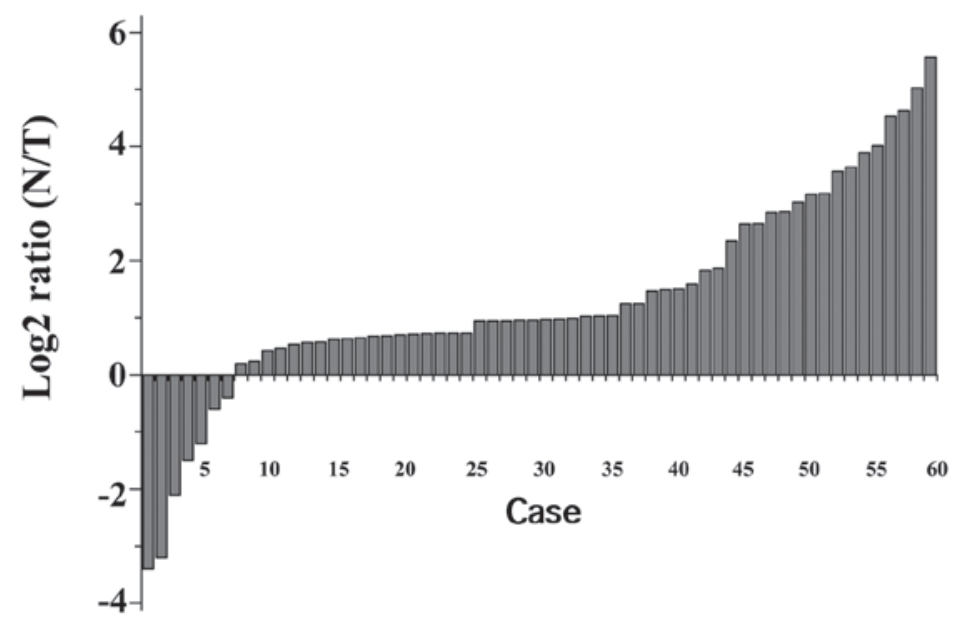

B

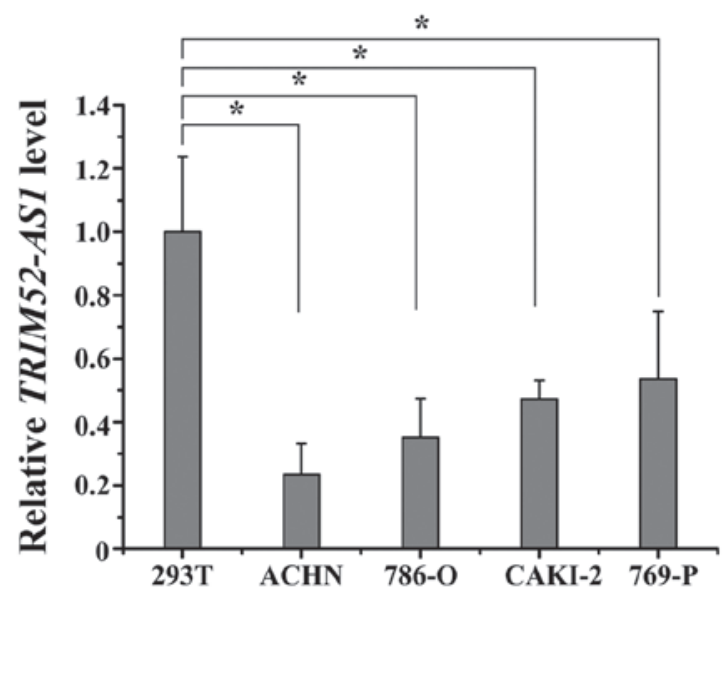

Figure 1. TRIM52-AS is downregulated in RCC tissues and cell lines. (A) RT-qPCR analysis of the expression of TRIM52-AS relative to the expression of GAPDH in RCC samples (T), compared with adjacent normal lung tissue samples (N) from 60 patients with RCC. The $2^{-\Delta \Delta C Q}$ method was used to analyze the data, and the data are shown in $\log 2$ (N/T). (B) RT-qPCR analysis of the expression levels of TRIM52-AS in 786-O, ACHN, 769-P and CAKI-2 RCC cell lines, compared with the normal $293 \mathrm{~T}$ kidney cell line. Data are expressed as the mean \pm standard deviation $(\mathrm{n}=3)$. * $\mathrm{P}<0.05$. RCC. renal cell carcinoma; RT-qPCR, reverse transcription-quantitative polymerase chain reaction.

the crystals. The results were measured at a wavelength of $490 \mathrm{~nm}$ (with $630 \mathrm{~nm}$ as the reference wavelength) using an ELISA microplate reader (Bio-Rad Laboratories, Inc., Hercules, CA, USA). Assays were repeated at least three times.

Cell migration assay. A wound scratch assay was used to assess the migratory ability of the 786-O and ACHN RCC cells in vitro. For the assay, $\sim 5 \times 10^{6}$ cells were seeded per 6-well dish and were transfected with TRIM52-AS1 shRNA (100 pmol) or TRIM52-AS1-pcDNA3.1+ $(4 \mu \mathrm{g})$ after $24 \mathrm{~h}$ using Lipofectamine 2000. At $6 \mathrm{~h}$ post-transfection, a vertical horizontal wound was made in the cell layer using a sterile $10 \mu \mathrm{l}$ pipette tip, and markers were included to allow observation of cells at the same point. The cells were then rinsed with phosphate-buffered saline (PBS) and cultured in an incubator at $37^{\circ} \mathrm{C}$. Images of the wounds were captured with a digital camera system (C3040-AD6; Olympus Corporation, Tokyo, Japan) 0 and $24 \mathrm{~h}$ following creation of the wounds at the same points. The wound widths $(1 \mathrm{~m})$ were measured using a standard caliper (Caliper; PerkinElmer, Inc., Waltham, MA, USA). The experiments were performed in triplicate and repeated at least three times.

Cell apoptosis assay. The extent of apoptosis was evaluated using an Annexin V-fluorescein isothiocyanate (FITC)/propidium iodide (PI) detection kit (Invitrogen; Thermo Fisher Scientific, Inc.). Following transfection of the ACHN and 786-O cells with the TRIM52-AS1 shRNA (200 pmol/well) or TRIM52-AS1-pcDNA3.1+ (4 $\mu \mathrm{g} /$ well) vector, the cells were collected, washed twice with pre-chilled PBS and re-suspended in $1 \mathrm{X}$ binding buffer ( $\mathrm{pH} 7.4 ; 10 \mathrm{mmol} / 1 \mathrm{HEPES}$, $140 \mathrm{mmol} / 1 \mathrm{NaCl}, 5 \mathrm{mmol} / 1 \mathrm{CaCl}_{2}$; Invitrogen; Thermo Fisher Scientific, Inc.), $48 \mathrm{~h}$ post-treatment. The aliquots were mixed with $10 \mu \mathrm{l}$ annexin V-FITC and $10 \mu \mathrm{l} \mathrm{PI}$ at room temperature for $15 \mathrm{~min}$. The apoptosis assay was performed using a flow cytometer (EPICS X1-4, Beckman, CA, USA). Each experiment was performed at least three times.

Statistical analysis. Statistical analysis was performed using SPSS 17.0 software (SPSS, Inc., Chicago, IL, USA). Statistical significance was determined using Student's $t$-test. For comparison of the expression levels of TRIM52-AS1 in matched tumor, vs. normal samples, a paired $t$-test was used. Data are expressed as the mean \pm standard deviation. $\mathrm{P}<0.05$ was considered to indicate a statistically significant difference.

\section{Results}

TRIM52-AS1 is downregulated in RCC tissues and cell lines. A previous study showed TRIM52-AS1 to be downregulated in RCC tissues, as determined by lncRNAs expression profiling $(16,17)$. To confirm the result of sequencing, RT-qPCR was used to quantify the expression levels of TRIM52-AS1 in 60 matched RCC tissue samples and adjacent normal tissue samples. The relative expression of TRIM52-AS1 [log2 $(\mathrm{N} / \mathrm{T})]$ is shown in Fig. 1A. The expression of TRIM52-AS1 in the RCC tissues was significantly lower, compared with that in the adjacent normal tissues. Furthermore, compared with normal kidney $293 \mathrm{~T}$ cells, TRIM52-AS1 was also downregulated in the 786-O and ACHN cell lines $(\mathrm{P}<0.05$; Fig. 1B). These results suggested that TRIM52-AS1 may act as a tumor suppressor gene in RCC.

Downregulation of TRIM52-AS1 inhibits cell proliferation in vitro. To analyze the function of TRIM52-AS1 in RCC using an MTT assay, either TRIM52-AS1 shRNA or the TRIM52-AS1-pcDNA3.1+ vector were transfected into the 786-O and ACHN cell lines. The optical density (OD) values of the TRIM52-AS1 shRNA or the TRIM52-AS1-pcDNA3.1+ vector-treated groups were measured at a wavelength of $490 \mathrm{~nm}$ (620 $\mathrm{nm}$ reference wavelength) using an ELISA 
A

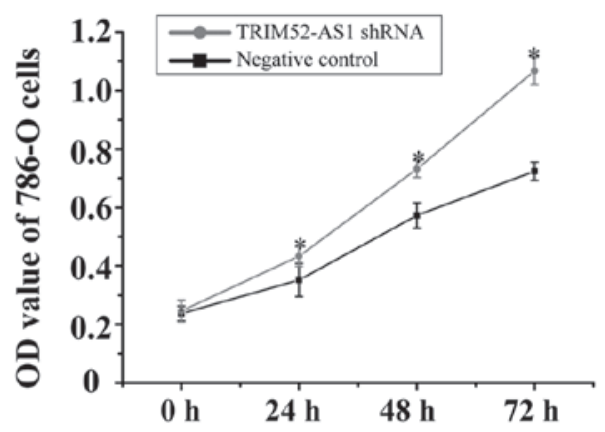

C

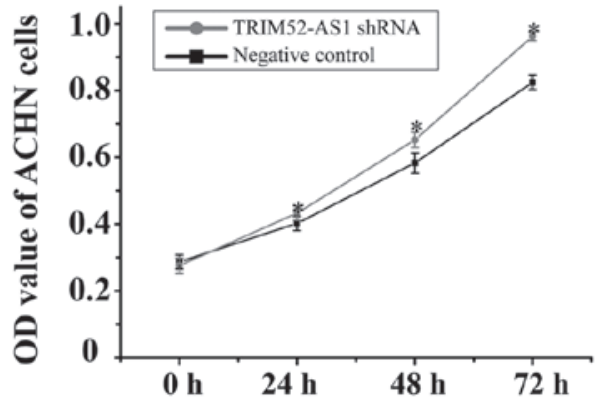

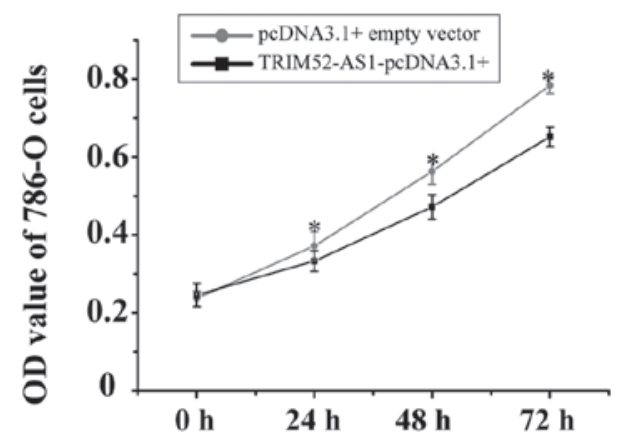

D

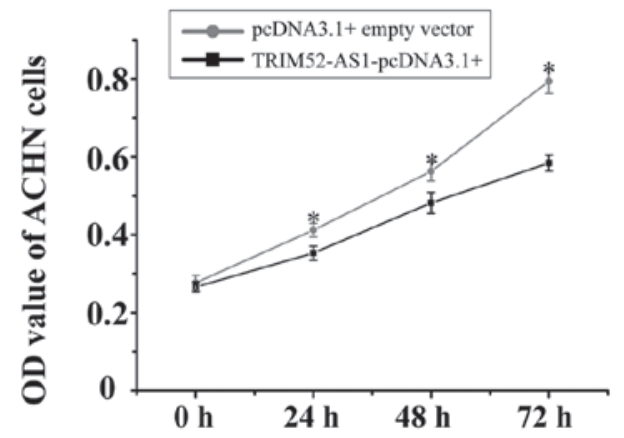

Figure 2. Effects of TRIM52-AS1 on cell proliferation. A 3-(4,5-dimethylthiazol-2yl)-2,5-diphenyl tetrazolium bromide assay was used to determine proliferation of 786-O and ACHN cells transfected with TRIM52-AS1 shRNA or TRIM52-AS1-pcDNA3.1+ vector. (A and B) Proliferation of 786-O cells. (C and D) Proliferation of ACHN cells. The experiments were performed in duplicate and repeated three times. Bars represent the mean \pm standard deviation. ${ }^{*} \mathrm{P}<0.05$. shRNA, small hairpin RNA; OD, optical density.

microplate reader at $0,24,48$ and $72 \mathrm{~h}$ post-transfection. The results demonstrated that the relative proliferation rates of the TRIM52-AS1 shRNA-transfected 786-O cell line were significantly increased by $42.8 \%$ (24 h), 31.2\% $(48 \mathrm{~h})$ and $55.2 \%(72 \mathrm{~h})$, whereas proliferation rates in the TRIM52-AS1-pcDNA3.1+ vector-transfected group were significantly decreased by $16.8 \%(24 \mathrm{~h}), 15.2 \%(48 \mathrm{~h})$ and $20.4 \%$ ( 72 h; Fig. 2A and B); The relative cell proliferation rates in the TRIM52-AS1 shRNA-transfected ACHN cell line were significantly increased, by $14.8 \%$ (24 h), $17.3 \%$ (48 h) and $29.2 \%$ (72 h), whereas proliferation rates in the TRIM52-AS1-pcDNA3.1+ vector-transfected group were significantly decreased by $21.5 \%$ (24 h), 30.6\% (48 h) and $54.7 \%$ (72 h; Fig. 2C and D). These results indicated that the downregulation of TRIM52-AS1 had a negative effect on cellular proliferation in RCC.

Downregulation of TRIM52-AS1 inhibits RCC cell migration in vitro. The effects of TRIM52-AS1 on cellular migration in RCC cells were observed using a wound scratch assay. As shown in Fig. 3, interference of the expression of TRIM52-AS1 increased the rate of migration, whereas the overexpression of TRIM52-AS1 decreased migration rate $(\mathrm{P}<0.05)$. The results demonstrated that the wound widths in the group of cells transfected with the TRIM52-AS1-pcDNA3.1+ vector were markedly wider than those in the TRIM52-AS1 shRNA group, which indicated that downregulation of TRIM52-AS1 inhibited the migration of RCC cells.

Downregulation of TRIM52-AS1 promotes RCC cell apoptosis in vitro. LncRNAs have been reported to be important in cell apoptosis, particularly in the escape of cancer cells from apoptosis (20-22). To determine the impact of TRIM52-AS1 on RCC cell apoptosis, flow cytometry was performed to detect the rate of apoptosis in the cells. As shown in Fig. 4, the apoptotic rates of the 786-O cells transfected with the TRIM52-AS1 shRNA and TRIM52-AS1-pcDNA3.1+ vector were 7.5 and $25.3 \%$, respectively, and the apoptotic rates of the ACHN cells were 5.1 and $15.3 \%$, respectively, which demonstrated that the downregulation of TRIM52-AS1 promoted RCC cell apoptosis.

\section{Discussion}

RCC is the second leading contributor to mortality rates among urological tumors. The reported incidence of RCC has increased in the USA over the past two decades $(23,24)$. Despite substantial improvements in cancer therapy, major limitations in the management $\mathrm{RCC}$ remain. $\mathrm{RCC}$ is characterized by its resistance to current standard therapies (25), and the identification of alternative treatment strategies remains a top priority.

LncRNAs are RNA transcripts of $>200$ nucleotides with no protein encoding functions. Increasing studies have indicated that the molecular mechanisms of carcinogenesis are not only relevant to protein-coding genes, but are also relevant to non-coding regulatory RNAs. Previous studies have shown that numerous lncRNAs are deregulated in various types of solid tumor, and that several lncRNAs can regulate cancer metastasis by directly targeting chromatin modification complexes, indicating that the abnormal expression of lncRNAs increases the chances of tumorigenesis and 
A
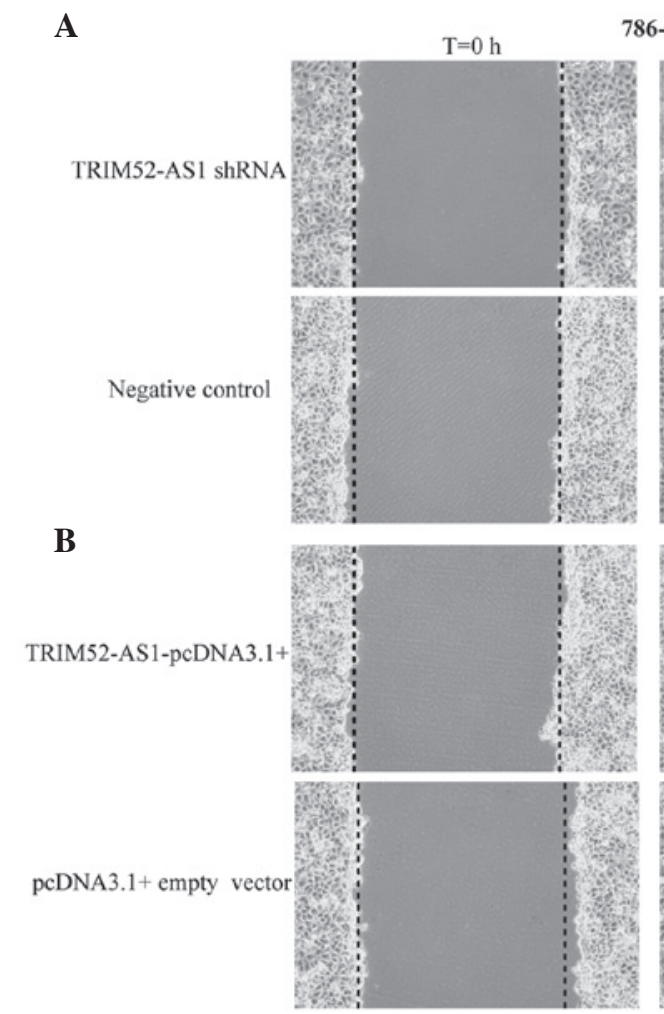

786-O
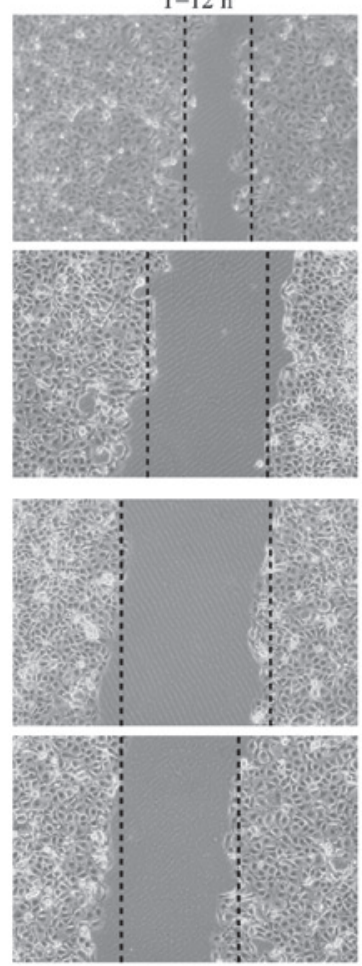
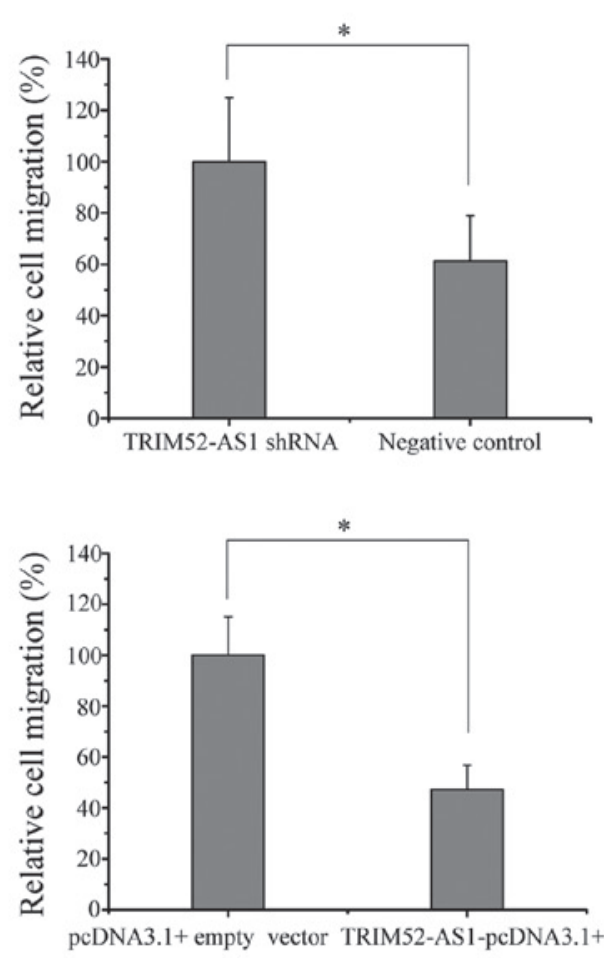

C

ACHN

$\mathrm{T}=0 \mathrm{~h}$

$\mathrm{T}=12 \mathrm{~h}$
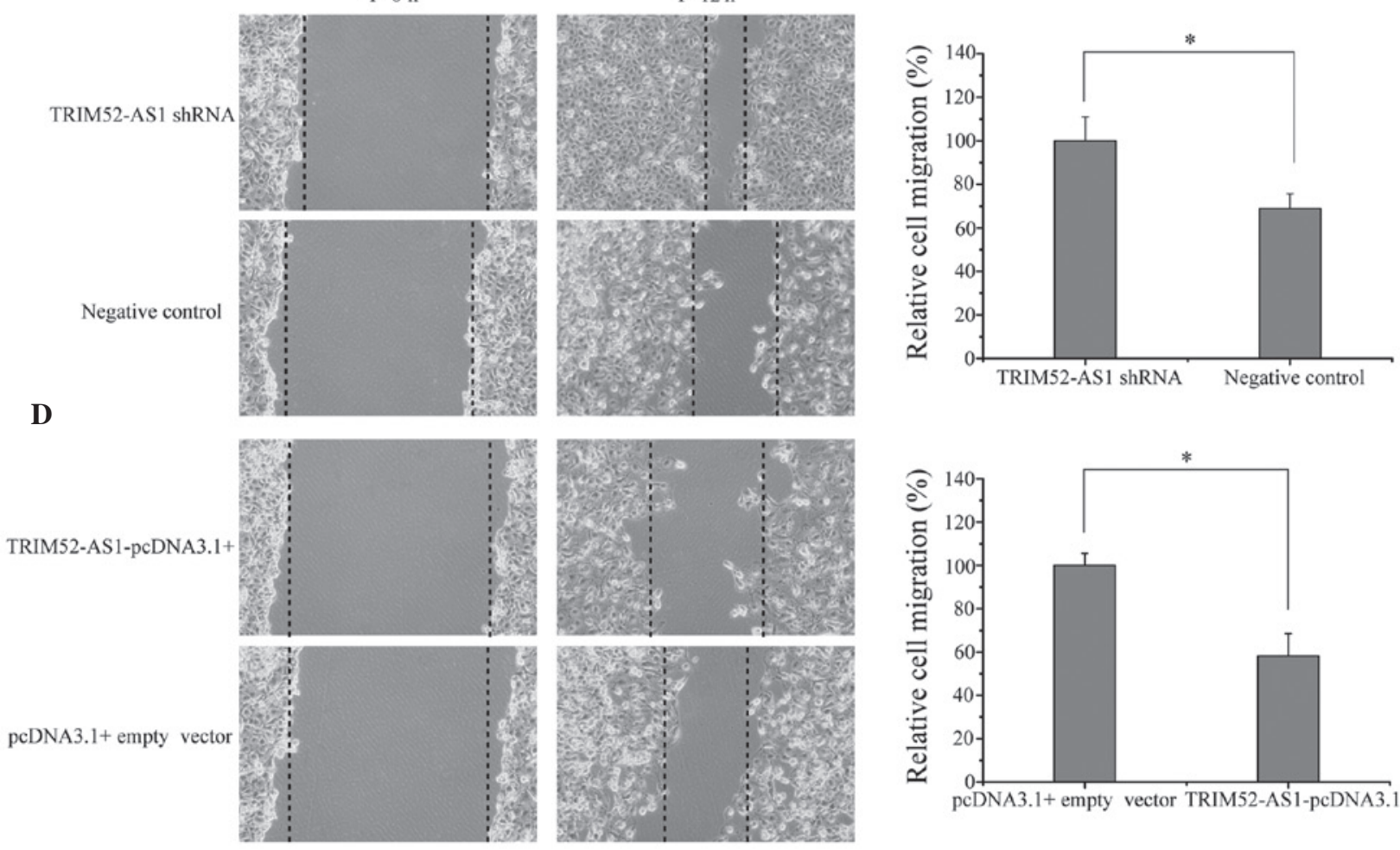

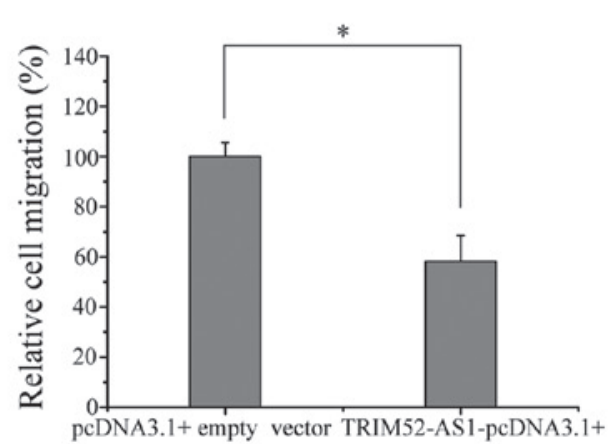

Figure 3. Downregulation of TRIM52-AS1 inhibits the migration of 786-O and ACHN cells. (A and B) Migration of 786-O cells transfected with TRIM52-AS1 shRNA or TRIM52-AS1-pcDNA3.1+ vector, respectively. (C and D) Migration of ACHN cells transfected with TRIM52-AS1 shRNA or TRIM52-AS1-pcDNA3.1+ vector, respectively. All experiments were performed three times, and representative images are shown. The dotted lines represent the migration front. Bars represent the mean \pm standard deviation. ${ }^{*} \mathrm{P}<0.05$. shRNA, small hairpin RNA; $\mathrm{T}$, time.

cancer development (26-29). For example, the overexpression of IncRNA HOTAIR is associated with breast cancer (30), upregulated MALAT1 contributes to bladder cancer (31), downexpression of lncRNA XIST is associated with glioblastoma (32) and upregulated PCAT-1 contributes to prostate cancer (33). 
A

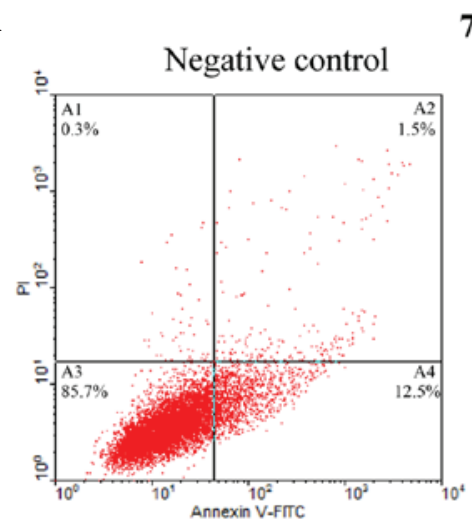

B

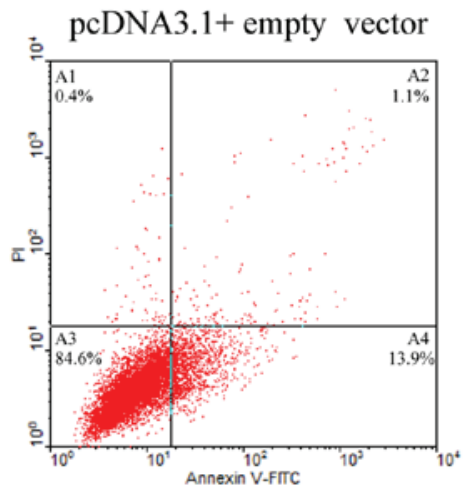

C

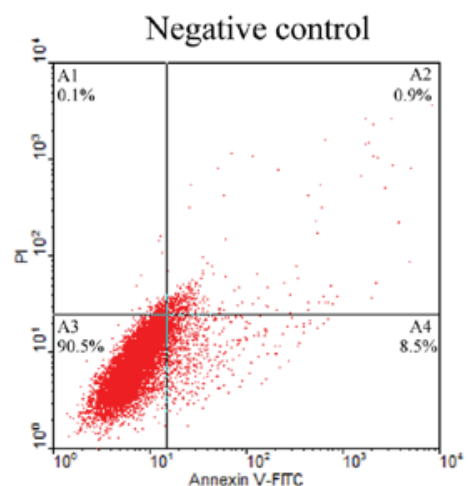

D

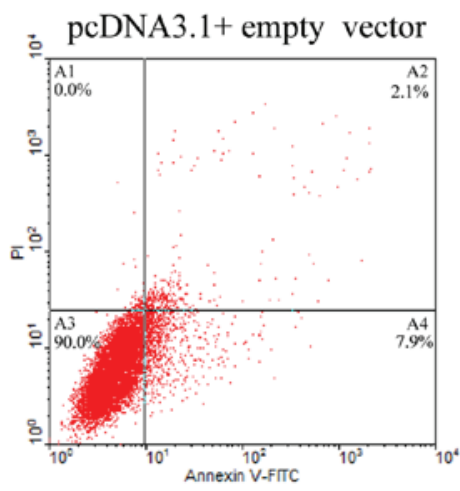

786-O
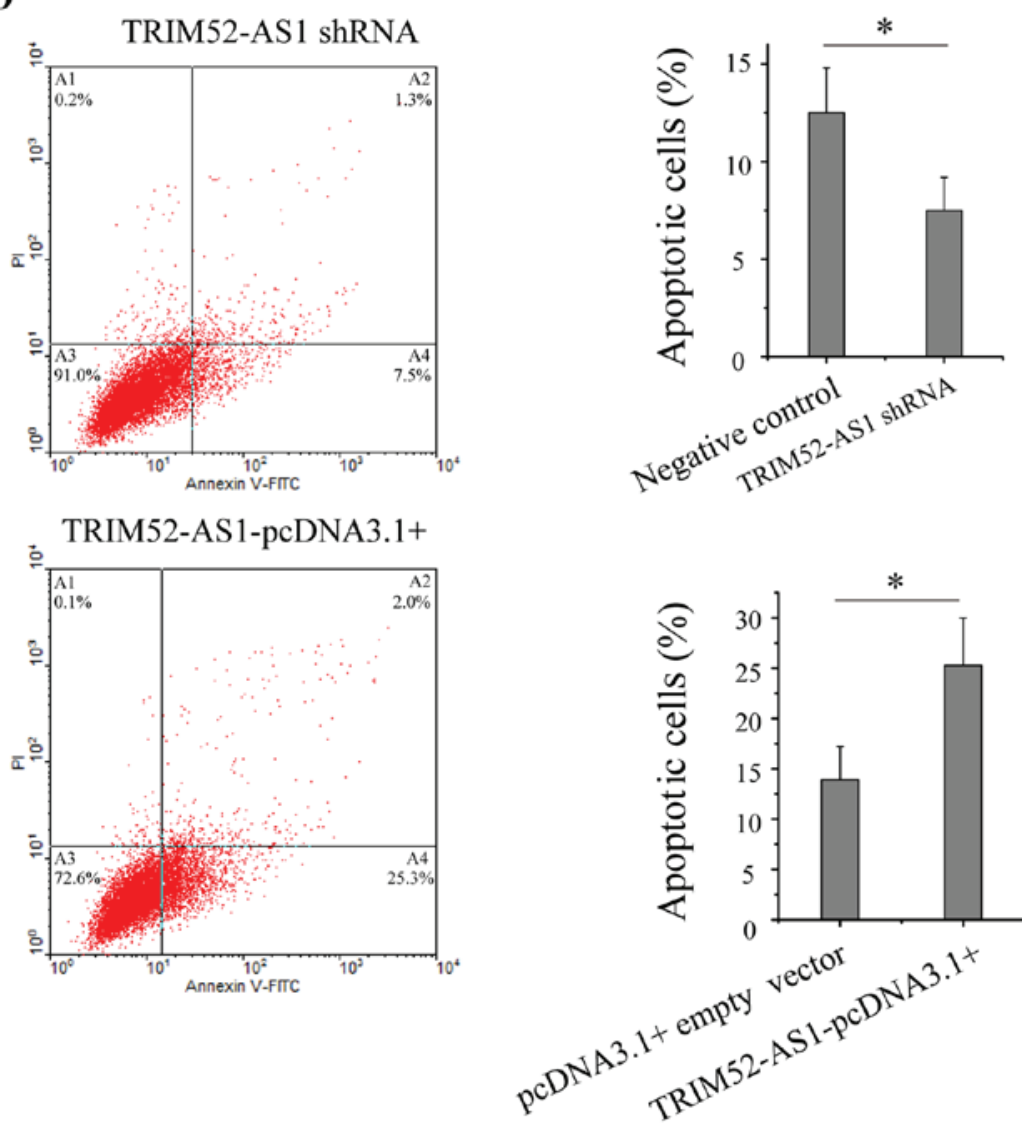

ACHN
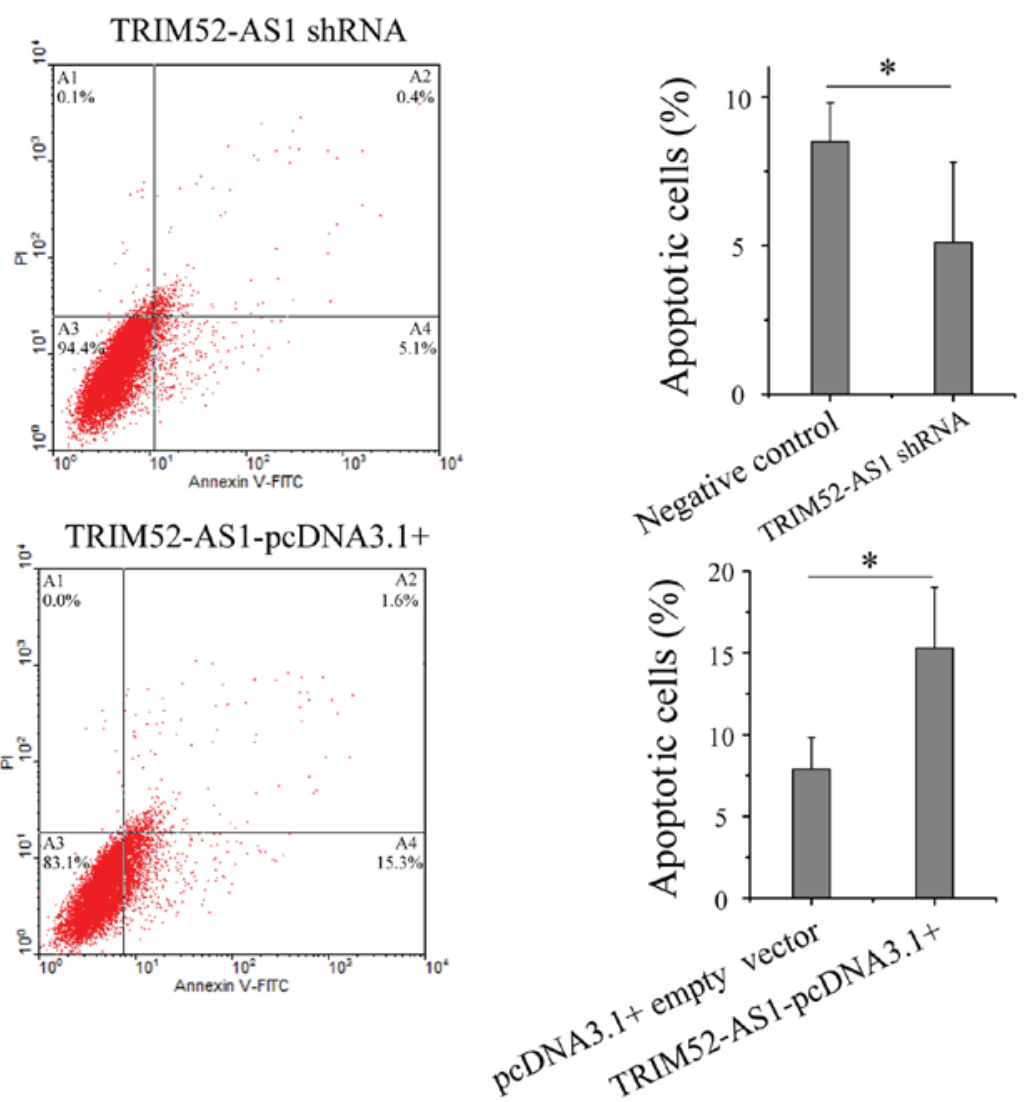

Figure 4. Flow cytometric analysis of apoptosis of 786-O and ACHN cells transfected with TRIM52-AS1 shRNA or TRIM52-AS1-pcDNA3.1+ vector. (A and B) 786-O cells transfected with TRIM52-AS1 shRNA or TRIM52-AS1-pcDNA3.1+ vector, respectively. (C and D) ACHN cells transfected with TRIM52-AS1 shRNA or TRIM52-AS1-pcDNA3.1+ vector, respectively. Each experiment was repeated three times with independent samples. Bars represent the mean \pm standard deviation. ${ }^{*} \mathrm{P}<0.05$. FITC, fluorescein isothiocyanate; PI, propidium iodide; shRNA, small hairpin RNA. A1: necrotic cells; A2: late apoptotic cells; A3: normal cells; A4: early apoptotic cells. 
Previous studies have indicated that TRIM52-AS1 is downregulated in RCC tissues, as detected by lncRNA expression profiling, As a common type of urological cancer, whether the abnormal expression of TRIM52-AS1 is associated with RCC carcinogenesis has not been reported previously. Therefore, the present study is the first, to the best of our knowledge to certify the expression of TRIM52-AS1 and examine its function in RCC. The results were consistent with previous sequencing, demonstrating that TRIM52-AS1 was significantly downregulated in RCC. In addition, the overexpression of TRIM52-AS1 in the 786-O and ACHN cell lines significantly inhibited cell proliferation and migration, and induced cell apoptosis. By contrast, the knockdown of its expression had the opposite effects. Together, these results suggested that TRIM52-AS acted as a tumor suppressor gene in the occurrence and development of RCC.

In conclusion, the present study revealed that TRIM52-AS1 was downregulated in RCC and was significantly involved in RCC by affecting cellular migration, proliferation and apoptosis. These results indicated TRIM52-AS1 as a promising biomarker and/or a therapeutic target for RCC, Further investigation is required to determine the molecular mechanisms underlying the effect of TRIM52-AS1 in RCC.

\section{Acknowledgements}

This study was supported by the Overseas Issue Foundation of Education Department In Heilongjiang Province (grant no. 1254HQ014) and The First Affiliated Hospital Of Harbin Medical University Foundation (grant no. 2014L01).

\section{References}

1. Jemal A, Siegel R, Xu J and Ward E: Cancer statistics, 2010. CA Cancer J Clin 60: 277-300, 2010.

2. Patel C, Ahmed A and Ellsworth P: Renal cell carcinoma: A reappraisal. Urol Nurs 32: 182-190. quiz 191, 2012.

3. Siegel R, Naishadham D and Jemal A: Cancer statistics, 2013. CA Cancer J Clin 63: 11-30, 2013.

4. Milowsky MI and Nanus DM: Chemotherapeutic strategies for renal cell carcinoma. Urol Clin North Am 30: 601-609. x, 2003.

5. Rouviere O, Bouvier R, Négrier S, Badet L and Lyonnet D: Nonmetastatic renal-cell carcinoma: is It really possible to define rational guidelines for post-treatment follow-up? Nat Clin Pract Oncol 3: 200-213, 2006.

6. Costa FF: Non-coding RNAs: Meet thy masters. Bioessays 32: 599-608, 2010

7. Zhang X, Gejman R, Mahta A, Zhong Y, Rice KA, Zhou Y, Cheunsuchon P, Louis DN and Klibanski A: Maternally expressed gene 3, an imprinted noncoding RNA gene, is associated with meningioma pathogenesis and progression. Cancer Res 70: 2350-2358, 2010

8. Gutschner T and Diederichs S: The hallmarks of cancer: A long non-coding RNA point of view. RNA Biol 9: 703-719, 2012.

9. Deng K, Guo X, Wang $\mathrm{H}$ and Xia J: The lncRNA-MYC regulatory network in cancer. Tumour Biol 35: 9497-9503, 2014.

10. Taft RJ, Pang KC, Mercer TR, Dinger M and Mattick JS: Non-coding RNAs: Regulators of disease. J Pathol 220: 126-139, 2010.

11. Zhang HM, Yang FQ, Chen SJ, Che J and Zheng JH: Upregulation of long non-coding RNA MALAT1 correlates with tumor progression and poor prognosis in clear cell renal cell carcinoma. Tumour Biol 36: 2947-2955, 2015.

12. Zhang HM, Yang FQ, Yan Y, Che JP and Zheng JH: High expression of long non-coding RNA SPRY4-IT1 predicts poor prognosis of clear cell renal cell carcinoma. Int J Clin Exp Pathol 7: 5801-5809, 2014.
13. Zhang ZZ, Shen ZY, Shen YY, Zhao EH, Wang M, Wang CJ, $\mathrm{Cao} \mathrm{H}$ and $\mathrm{Xu}$ J: HOTAIR long noncoding RNA promotes gastric cancer metastasis through suppression of Poly $\mathrm{r}(\mathrm{C})$ Binding Protein (PCBP) 1. Mol Cancer Ther 14: 1162-1170, 2015.

14. Ma MZ, Chu BF, Zhang Y, Weng MZ, Qin YY, Gong W and Quan ZW: Long non-coding RNA CCAT1 promotes gallbladder cancer development via negative modulation of miRNA-218-5p. Cell Death Dis 6: e1583, 2015.

15. Li JY, Ma X and Zhang CB: Overexpression of long non-coding RNA UCA1 predicts a poor prognosis in patients with esophageal squamous cell carcinoma. Int J Clin Exp Pathol 7: 7938-7944, 2014.

16. Yu G, Yao W, Wang J, Ma X, Xiao W, Li H, Xia D, Yang Y, Deng $\mathrm{K}$, Xiao $\mathrm{H}$, et al: LncRNAs expression signatures of renal clear cell carcinoma revealed by microarray. PLoS One 7: e42377, 2012.

17. Fachel AA, Tahira AC, Vilella-Arias SA, Maracaja-Coutinho V, Gimba ER, Vignal GM, Campos FS, Reis EM and Verjovski-Almeida S: Expression analysis and in silico characterization of intronic long noncoding RNAs in renal cell carcinoma: Emerging functional associations. Mol Cancer 12: 140, 2013.

18. Martínez- Salamanca JI, Huang WC, Millán I, Bertini R, Bianco FJ, Carballido JA, Ciancio G, Hernández C, Herranz F and Haferkamp A: Prognostic impact of the 2009 UICC/AJCC TNM staging system for renal cell carcinoma with venous extension. Eur Urol 59: 120- 127, 2011.

19. Schmittgen TD and Livak KJ: Analyzing real-time PCR data by the comparative C(T) method. Nat Protoc 3: 1101-1108, 2008.

20. Nie FQ, Sun M, Yang JS, Xie M, Xu TP, Xia R, Liu YW, Liu XH, Zhang EB, Lu KH and Shu YQ: Long noncoding RNA ANRIL promotes non-small cell lung cancer cell proliferation and inhibits apoptosis by silencing KLF2 and P21 expression. Mol Cancer Ther 14: 268-277, 2015.

21. Xu WH, Zhang JB, Dang Z, Li X, Zhou T, Liu J, Wang DS, Song WJ and Dou KF: Long non-coding RNA URHC regulates cell proliferation and apoptosis via ZAK through the ERK/MAPK signaling pathway in hepatocellular carcinoma. Int J Biol Sci 10: 664-676, 2014

22. Han Y, Yang YN, Yuan HH, Zhang TT, Sui H, Wei XL, Liu L, Huang P, Zhang WJ and Bai YX: UCA1, a long non-coding RNA up-regulated in colorectal cancer influences cell proliferation, apoptosis and cell cycle distribution. Pathology 46: 396-401, 2014.

23. Taneja SS: Re: Cancers with increasing incidence trends in the United States: 1999 through 2008. J Urol 188: 1120-1121, 2012.

24. Underwood JM, Richards TB, Henley SJ, Momin B, Houston K, Rolle I, Holmes C and Stewart SL: Decreasing trend in tobacco-related cancer incidence, United States 2005-2009. J Community Health 40: 414-418, 2015.

25. Cohen HT and McGovern FJ: Renal-cell carcinoma. N Engl J Med 353: 2477-2490, 2005.

26. Chen LL and Zhao JC: Functional analysis of long noncoding RNAs in development and disease. Adv Exp Med Biol 825: 129-158, 2014.

27. Yang G, Lu X and Yuan L: LncRNA: A link between RNA and cancer. Biochim Biophys Acta 1839: 1097-1109, 2014.

28. Huang T, Alvarez A, Hu B and Cheng SY: Noncoding RNAs in cancer and cancer stem cells. Chin J Cancer 32: 582-593, 2013.

29. Cheetham SW, Gruhl F, Mattick JS and Dinger ME: Long noncoding RNAs and the genetics of cancer. Br J Cancer 108: 2419-2425, 2013.

30. Zhang J, Zhang P, Wang L, Piao HL and Ma L: Long non-coding RNA HOTAIR in carcinogenesis and metastasis. Acta Biochim Biophys Sin (Shanghai) 46: 1-5, 2014.

31. Han Y, Liu Y, Zhang H, Wang T, Diao R, Jiang Z, Gui Y and Cai Z: Hsa-miR-125b suppresses bladder cancer development by down-regulating oncogene SIRT7 and oncogenic long non-coding RNA MALAT1. FEBS Lett 587: 3875-3882, 2013.

32. Yao Y, Ma J, Xue Y, Wang P, Li Z, Liu J, Chen L, Xi Z, Teng H, Wang Z, et al: Knockdown of long non-coding RNA XIST exerts tumor-suppressive functions in human glioblastoma stem cells by up-regulating miR-152. Cancer Lett 359: 75-86, 2015.

33. Prensner JR, Chen W, Han S, Iyer MK, Cao Q, Kothari V, Evans JR, Knudsen KE, Paulsen MT, Ljungman M, et al: The long non-coding RNA PCAT-1 promotes prostate cancer cell proliferation through cMyc. Neoplasia 16: 900-908, 2014. 